\title{
Adult Romantic Attachment, Negative Emotionality, and Depressive Symptoms in Middle Aged Men: A Multivariate Genetic Analysis
}

\author{
Carol E. Franz • Timothy P. York • Lindon J. Eaves • Elizabeth Prom-Wormley • \\ Kristen C. Jacobson • Michael J. Lyons • Michael D. Grant • Hong Xian • \\ Matthew S. Panizzon · Erica Jimenez $\cdot$ William S. Kremen
}

Received: 29 June 2010/Accepted: 6 December 2010/Published online: 7 January 2011

(C) The Author(s) 2011. This article is published with open access at Springerlink.com

\begin{abstract}
Adult romantic attachment styles reflect ways of relating in close relationships and are associated with depression and negative emotionality. We estimated the extent to which dimensions of romantic attachment and negative emotionality share genetic or environmental risk factors in 1,237 middle-aged men in the Vietnam Era Twin Study of Aging (VETSA). A common genetic factor largely explained the covariance between attachment-related anxiety, attachment-related avoidance, depressive symptoms, and two measures of negative emotionality: StressReaction (anxiety), and Alienation. Multivariate results
\end{abstract}

Edited by Richard Rose.

Results were presented at the annual meeting of the Behavior Genetics Association in Louisville, KY, June 25-28, 2008.

C. E. Franz $(\bowtie) \cdot$ M. S. Panizzon · E. Jimenez · W. S. Kremen Department of Psychiatry, University of California San Diego, 9500 Gilman Drive, MC0738, La Jolla, CA 92093-0738, USA e-mail: cfranz@ucsd.edu

T. P. York · L. J. Eaves · E. Prom-Wormley

Virginia Institute for Psychiatric and Behavioral Genetics,

Virginia Commonwealth University, Richmond, VA, USA

K. C. Jacobson

Department of Psychiatry and Behavioral Neuroscience,

The University of Chicago, Chicago, IL, USA

M. J. Lyons · M. D. Grant

Department of Psychology, Boston University, Boston, MA, USA

H. Xian

Washington University, St. Louis, MO, USA

W. S. Kremen

VA Healthcare System, Psychiatry Service, San Diego, CA, USA supported genetic and environmental differences in attachment. Attachment-related anxiety and attachmentrelated avoidance were each influenced by additional genetic factors not shared with other measures; the genetic correlation between the attachment measure-specific genetic factors was 0.41 , indicating some, but not complete overlap of genetic factors. Genetically informative longitudinal studies on attachment relationship dimensions can help to illuminate the role of relationship-based risk factors in healthy aging.

Keywords Adult attachment - Depression · Neuroticism · Negative emotionality · Personality - Twin studies .

VETSA - Experiences in Close Relationships Inventory

\section{Introduction}

Insecure attachment relationships are thought to cause psychological distress, such as feelings of depression or anxiety (Bowlby 1982; Schaie and Zuo 2000; Seeman et al. 2001). People who express abandonment fears and worry about the reliability of others in times of need are considered to be high in anxious attachment, while emotional detachment or wariness about relying on another person characterizes avoidant attachment (Brennan et al. 1998). For adults, positive attachment relationships with an intimate partner appear to be psychologically and physically beneficial (Hazan and Shaver 1987; Mikulincer and Shaver 2007; Shaver et al. 1988). Depression, neuroticism, and relationship difficulties have shared risk factors in men (Kendler et al. 2006a, b). In this study, we examine the role of genetic and environmental influences on associations among dimensions of adult attachment, depressive symptoms and manifestations of negative emotionality in middle aged men. 
Few twin studies examine the extent of genetic influences on adult romantic attachment, possibly because theory emphasizes the role of the family environment in shaping attachment style (Bowlby 1982, 1988). In three adult samples, the magnitude of genetic influences on indicators of anxious romantic attachment was low to moderate (25-46\%) (Brussoni et al. 2000; Crawford et al. 2007a, b; Donnellan et al. 2008; Torgersen et al. 2007). Brussoni et al. (2000) studied 116 monozygotic (MZ) and 104 dizygotic (DZ) same sex twin pairs (ages 16-79) who were categorized into four attachment styles based on cutoff scores on the Relationship Scales Questionnaire (Griffin and Bartholomew 1994) a self-report measure of adult attachment (Brussoni et al. 2000). Strongest additive genetic influences were found for anxious (fearful) attachment (43\%); unique environmental influences-that is, life experiences not shared by the twins-accounted for the remaining variance $(57 \%)$. An environmental model was the best fitting model for dismissive/avoidant attachment: common environmental influences accounted for $29 \%$ of the variance and unique environment the rest (71\%). This sample was predominantly female. Using continuous measures of attachment from the same sample, Crawford et al. (2007a, b), found no genetic influences on attachment-related avoidance. Consistent with the earlier categorical approach, common environmental influences accounted for $30 \%$ of the variance and unique environmental influences accounted for the remaining variance (Crawford et al. 2007a, b). Attachment-related anxiety and attachment-related avoidance were correlated 0.29.

Donnellan et al. (2008), however, reported moderate heritability for a continuous measure of attachment-related avoidance, with genetic influences accounting for $39 \%$ of the phenotypic variance in a sample of predominantly college age female twins (Donnellan et al. 2008). Finally, there was higher concordance for secure versus nonsecure attachment style among monozygotic (MZ) compared with dizygotic (DZ) twins in a study using an interview approach to assessing attachment (Torgersen et al. 2007). Heritability accounted for $46 \%$ of the variance, common environment $36 \%$, and nonshared $18 \%$. These results were not significant, however, possibly because the small sample was small ( $N=41$ pairs), the interview was not exclusively focused on adult romantic attachment or because all of the nonsecure styles were collapsed into a single style. Collapsing different forms of nonsecure attachment into a single measure may obscure distinctions among dimensions of attachment. In summary, research consistently finds that both heredity and nonshared environment contribute to anxious attachment style in adulthood but the role of genes and environment are less clear for avoidant styles of adult attachment.

Measures of adult attachment-related anxiety and attachment-related avoidance, depressive symptoms, and characteristics reflecting negative emotionality (e.g., neuroticism, dysregulated emotionality, anxious personality) have strong phenotypic correlations (Bifulco et al. 2002a, b; Crawford et al. 2007a, b; Mikulincer and Shaver 2007; Noftle and Shaver 2006). Genetic and environmental overlap between measures of attachment and measures reflecting negative emotionality was examined in two adult twin samples. Donnellan et al. (2008) found significant genetic correlations ( $\mathrm{Rg}$ ) between attachment-related anxiety and neuroticism $(\mathrm{Rg}=0.35)$ as well as small genetic overlap between attachment-related avoidance and neuroticism $(\mathrm{Rg}=0.11)$. Crawford et al. found that shared genetic influences explained much of the phenotypic association (mean genetic correlation $=0.75$ ) between attachment-related anxiety and personality disorder dimensions reflecting emotional dysregulation. Unique environmental correlations were lower (ranging from 0.18 to 0.37 ), suggesting that although emotional dysregulation and attachment-related anxiety share genetic risk, different environmental factors influence each characteristic. Since there were virtually no significant genetic influences on attachment-related avoidance and no common environmental influences on the personality disorder measures, overlap between these measures was primarily accounted for by unshared environmental influences. Neither twin study examined the association between depressive symptoms and attachment.

More attention has been given to the study of genetic and environmental influences on depressive symptoms and measures reflecting negative emotionality. In men, genetic correlations between measures of depressive symptoms and neuroticism range from 0.37 to 0.99 depending on whether patient or non-patient samples are used, and the type of instrument (Fanous et al. 2007; Hettema et al. 2006; Kendler et al. 1987a, b; Middeldorp et al. 2005). In general, it appears that a non-specific "genetic-distress" factor explains the shared covariance between depression and anxiety in a normal population. In essence, the same genes that influenced depressive symptoms also influenced anxiety symptoms; however, environmental factors influencing depressive symptoms do not appear to affect symptoms of anxiety and vice versa (Kendler et al. 1987a, b; Middeldorp et al. 2008). Depressive symptoms and neuroticism both are moderately heritable. The contribution of genetic influences on adult depression symptoms ranges from 16 to $37 \%$ (Kendler et al. 2006a, b; Lyons et al. 1998). The heritability estimates of the personality trait of neuroticism/ negative emotionality (variously defined) range from 30 to $60 \%$ and may be higher in men than in women (Eaves et al. 1998; Hettema et al. 2004; Jang et al. 1996; Kendler et al. 2006a, b). Understanding the etiology of depression and related disorders during aging may be illuminated by estimation of genetic and environmental effects shared 
between depressive symptoms and commonly used measures of adult romantic attachment (O'Connor et al. 2000).

Prior twin studies of adult attachment have been limited in their applicability to older adults (Shaver and Mikulincer 2004). Participants in previous studies were predominantly young adult women (Brussoni et al. 2000; Crawford et al. 2007a, b; Donnellan et al. 2008; Torgersen et al. 2007), which makes generalizations to older adults, especially men, difficult. In addition, studies used different measures of attachment and some even collapse anxious and avoidant attachment into a single measure. Similarly, other studies use conglomerate measures of neuroticism which differ in composition from study to study. If there are distinct genetic and/or environmental influences that characterize different attachment dimensions (e.g., anxious vs. avoidant)—or different manifestations of negative emotionality-that information is likely obscured by composite measures.

Our goal was to extend the literature on romantic attachment by using a twin study to examine how and why dimensions of attachment-related anxiety and avoidance are associated with depressive symptoms and other manifestations of negative emotionality in middle aged men. We used a multivariate twin approach to examine the structure of the genetic and environmental covariance of these related measures. This approach allows us to examine whether: (a) dimensions of attachment-related anxiety and avoidance have common genetic and environmental underpinnings or are etiologically distinct, and (b) the extent to which dimensions of attachment can be distinguished from measures of psychological distress.

\section{Method}

\section{Participants}

We recruited Vietnam Era Twin Study of Aging (VETSA) participants from 3322 twin pairs who participated in a previous epidemiologic study (Tsuang et al. 2001). The VETSA study focuses on genetic and environmental influences on cognitive aging; measures of adult romantic attachment, depressive symptoms and personality were included as risk and preventive factors important in aging (Kremen et al. 2006). Both members of a twin pair had to agree to participate and had to be between ages 51 and 60 (mean age $=55.4$; SD 2.47). The majority of participants $(68 \%)$ did not serve in combat or in Vietnam (Eisen et al. 1987).

Procedures and materials

Participants completed questionnaires at home and brought them to the University of California, San Diego or Boston
University on the testing day (99\% return rate). Institutional Review Board approval was obtained at all sites; all participants provided written informed consent.

We assessed dimensions of romantic attachment with the Experiences in Close Relationships Inventory (ECRI; Brennan et al. 1998). The 36 item ECRI yields two 18 item subscales (attachment-related anxiety and attachmentrelated avoidance: $\alpha>0.90$ ) with established validity in numerous college and adult samples (Brennan et al. 1998; Mikulincer and Shaver 2007). Responses ranged from one (strongly disagree) to seven (strongly agree). High scores on the attachment anxiety dimension indicate intense worries about separation and fear of abandonment by an intimate partner (e.g., "I get frustrated if romantic partners are not available when I need them"). High scores on the attachment avoidance dimension suggest distancing from emotional connections (e.g., "I prefer not to show a partner how I feel deep down"). The attachment-related avoidance and anxiety subscales are continuous dimensions rather than discrete attachment types (Fraley and Waller 1998). We assessed depressive symptoms with the Center for Epidemiologic Studies Depression Scale (CES-D; Radloff 1977). The CES-D comprises 20 items concerning the frequency of specific moods and behaviors during the past week; it has good reliability $(\alpha>0.92)$ and is highly correlated with indicators of major depression (Rush et al. 2000).

Negative emotionality measures included the StressReaction and Alienation subscales from Tellegen's Multidimensional Personality Questionnaire factor-form NZ; the NZ version is considered to be very similar to the Brief Form (Caspi 2000; Caspi et al. 1997; Krueger et al. 2000; Patrick et al. 2002). Persons high in Stress-Reaction tend to be nervous, prone to worry, and easily upset (14 items; $\alpha=0.86$ ). Persons high on Alienation (17 items; $\alpha=0.86$ ) report feeling unfairly treated, or taken advantage of by others. Validity of the psychometric properties of the MPQ is well documented (Krueger et al. 2000; Patrick et al. 2002; Tellegen 1985). Log transformations were used to improve the approximation to normality for all five variables.

Zygosity was determined using a combination of DNA testing (examination of 25 satellite markers), questionnaire and blood group methods; there was 95\% agreement between the DNA and questionnaire methods (Eisen et al. 1989; Nichols and Bilbro 1966).

Multivariate statistical analysis methods

A series of structural equation models were tested to determine the structure of the genetic and environmental covariance of the five measures (as implemented in $\mathrm{Mx}$ 1.66) (Neale et al. 2002). Optimization of the data used full 
information maximum likelihood to estimate model parameters. The use of maximum likelihood to measure model fit allows for testing of specific hypotheses by comparing a model and nested submodels using the chisquare statistic. Model fit using an unstructured model that allowed each variance and covariance to take its own value in MZ and DZ twins (i.e., a fully saturated model) was tested against a full Cholesky model where these statistics are assumed to be equal (see Table 3, Models 1 and 2). Since there were no significant differences between the unstructured model and the Cholesky, subsequent submodels were compared to the full Cholesky. In addition to model fit, model parsimony was assessed using Akaike's Information Criterion (AIC) and Bayesian Information Criterion (BIC) for each submodel (Akaike 1987; Schwarz 1978). The AIC is a statistic that balances both goodnessof-fit and parsimony; the BIC reflects how efficiently the parameterized model predicts the data and penalizes overly complex models. Submodels with smaller AIC and BIC values are preferred. The full Cholesky model factors the phenotypic variance/covariance into components of variance and covariance due to additive genetic (A) effects, common or shared environmental effects (C) and nonshared environmental effects $(\mathrm{E})$. This model has the same number of independent factors as the number of variables in the model.
Alternate models were tested to recapture the observed genetic and environmental covariance structure produced in the Cholesky model. For each of the A, C, and E components, we systematically compared the fit of Cholesky (Ch), Common Factor (F), and Measure-Specific (S) models. Figure 1 displays an example of a Common Factor model for the genetic influences in this study. Figure 2 displays an example of a Cholesky decomposition for the environmental factors in this study.

\section{Results}

\section{Descriptive statistics}

Questionnaire data were available from 1,226 of the 1,237 participants (336 MZ pairs; $277 \mathrm{DZ}$ pairs). Most men were married (80\%) and worked full time (Table 1); 6\% had never married. When sample demographics are compared with census figures, this sample appears representative of its age group of American men (Franz et al. in press).

The sample had relatively low scores on attachmentrelated anxiety and avoidance dimensions, few depressive symptoms on the CES-D, and low levels of Stress-Reaction and Alienation (Table 2). Depressive symptom scores for the sample were comparable to other community based

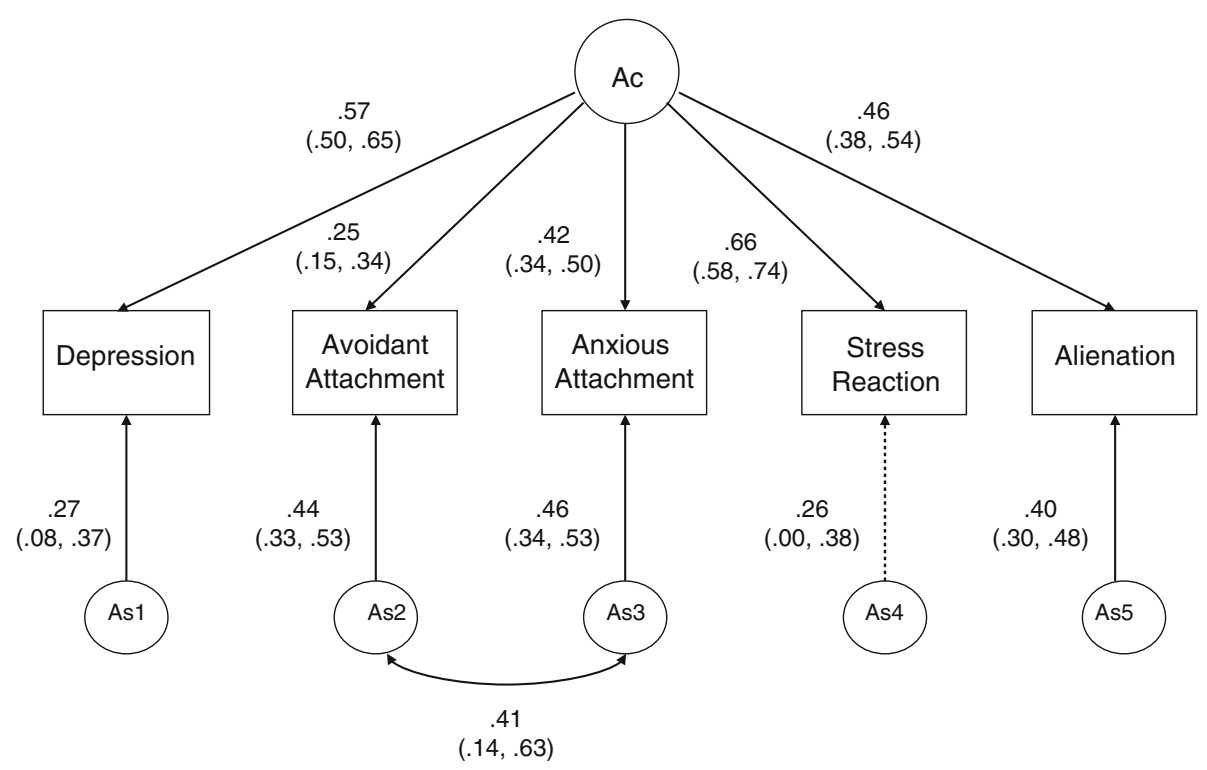

Fig. 1 Standardized parameter estimates for genetic factors. Model depicting relationships among genetic factors based on best fitting model (Model 10): a common genetic factor plus specific factors, with additional parameter accounting for the commonality between the attachment measures. CI Confidence intervals; Ac common genetic factor; As1-As5 specific genetic factors. Rectangles represent the five measures in this study; paths are represented as lines with arrows between circles (common and specific genetic factors) and rectangles, standardized parameter estimates and confidence intervals are beside each path. Parameter estimates designated by path coefficients are equivalent to factor loadings for each measured variable on the underlying latent factor (paths between $A c$ and rectangles). In addition, this figure also shows measure-specific influences (parameter estimates beside paths between As1, As2, As3, As4, and As5) and rectangles. These specific factors account variation in each measure above and beyond what is accounted for by the common latent factor, but do not contribute to covariance among measures. All paths, except As4, are significant 


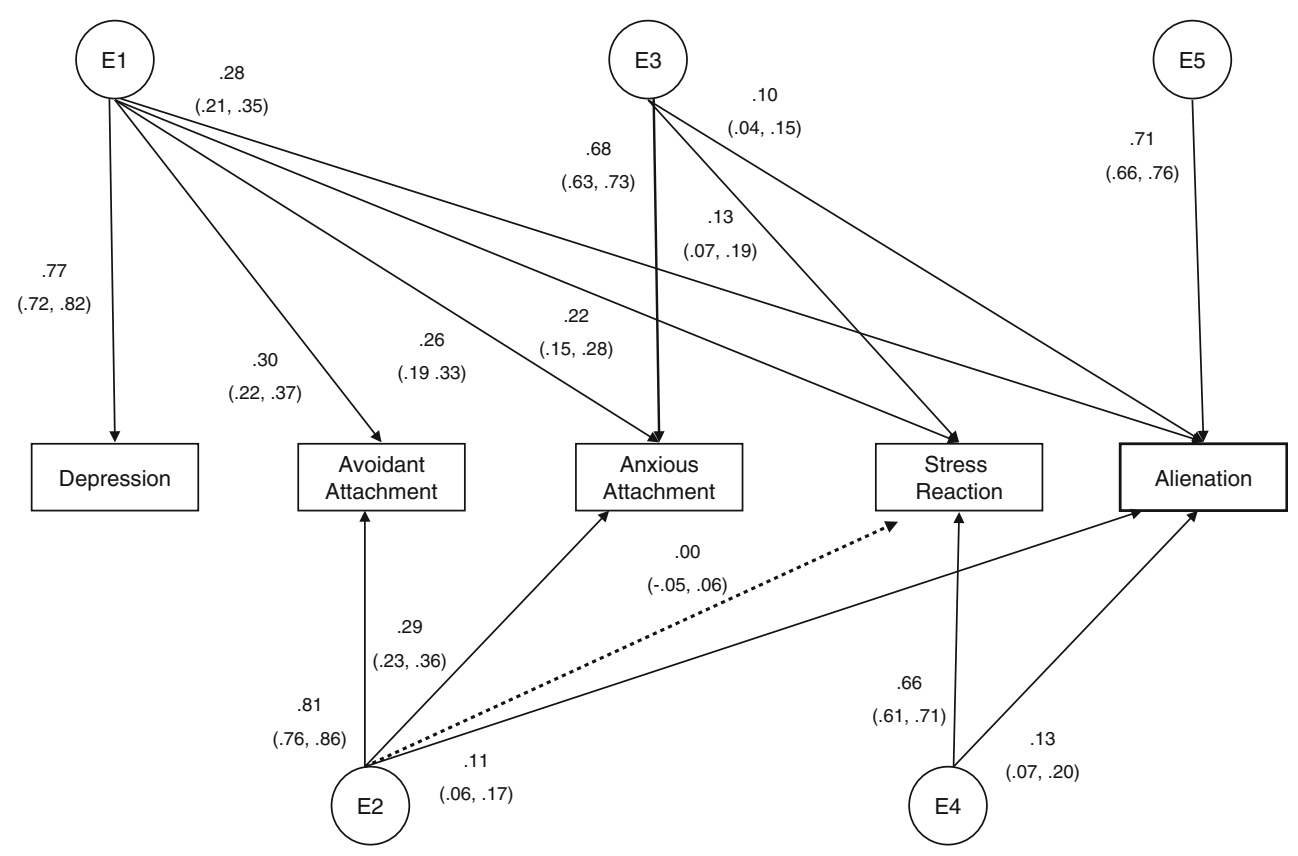

Fig. 2 Standardized parameter estimates for unique environmental factors. Cholesky factorization model depicting relationships among unique environmental factors. $C I$ Confidence intervals; $E 1-E 5$ unique environment factors. Rectangles represent the five measures in this study; paths are represented as lines with arrows from circles (unique

non-patient samples (Radloff 1977). We found significant phenotypic correlations among all five measures (Table 2) ranging from $r=0.61, p<0.0001$ (CES-D and StressReaction) to $r=0.27, p<0.001$ (avoidant attachment and Stress-Reaction). Attachment-related anxiety and avoidance were correlated $0.42(p<0.0001)$.

\section{Cross-twin, cross-trait correlations}

Table 3 shows the cross-trait, cross-twin correlations for the five measures. As expected, given the similarity among the measures, most of the correlations are significant. Withintwin correlations are roughly comparable for $\mathrm{MZ}$ and $\mathrm{DZ}$ twins; for instance, the association between CES-D symptoms and anxious attachment is 0.45 and 0.40 for the $\mathrm{MZ}$ and DZ "A" twins respectively. Examination of the pattern of cross-twin, cross-trait and within-trait correlations shows that associations for the MZ twin pairs are consistently somewhat stronger than those for DZ twins. The pattern of correlations suggests there are genetic influences on the measures and genetic overlap between the measures. For example, depression symptoms of the MZ "A" twins significantly influence the depression symptoms of the co-twins $(r=0.41)$; the correlation is nearly twice that of the correlations between the DZ twin pairs $(r=0.27)$. Similarly, for MZ co-twins, depressive symptoms of one twin are significantly correlated with the avoidant attachment of the brother and vice versa $(r=0.14$ and 0.19$)$; parallel environmental factors) to rectangles; standardized parameter estimates and confidence intervals are beside each path. All paths, with the exception of the path between E2 and SR, are significant. Unique environment includes measurement error

Table 1 Sample demographics

\begin{tabular}{ll}
\hline Marital status & \\
Married & $80 \%$ \\
Divorced/separated & $14 \%$ \\
Never married & $6 \%$ \\
Education & \\
$\quad \leq$ High school degree & $43 \%$ \\
Some college & $28 \%$ \\
$\geq$ College degree & $29 \%$ \\
Employment & \\
Full-time & $92.2 \%$ \\
Part-time & $1.6 \%$ \\
Other (e.g., unemployed, retired) & $6.2 \%$ \\
Occupation & \\
Service/manual labor & $39 \%$ \\
Small business/semi-professional & $46 \%$ \\
Professional & $15 \%$ \\
Ethnicity & \\
Caucasian & $89 \%$ \\
African-American & $4 \%$ \\
Hispanic & $3 \%$ \\
Other & \\
Median family income & \\
& \\
&
\end{tabular}

correlations for DZ twins are 0.09 and 0.02. Multivariate twin analyses can most effectively disentangle the genetic and environmental associations among these measures. 
Table 2 Descriptive statistics and phenotypic correlations

\begin{tabular}{lllllll}
\hline Measure & Mean (SD) & 1 & 2 & 3 & 4 & 5 \\
\hline 1. Depression symptoms & $8.13(8.09)$ & & & & \\
2. Avoidant attachment & $2.64(1.05)$ & 0.38 & & & \\
3. Anxious attachment & $2.84(1.09)$ & 0.48 & 0.42 & & \\
4. Stress-reaction & $4.55(3.78)$ & 0.61 & 0.27 & 0.49 & \\
5. Alienation & $2.53(3.32)$ & 0.54 & 0.29 & 0.43 & 0.50 \\
\hline
\end{tabular}

Note. Means presented in this table are untransformed. All correlations are significant at $p<0.001$. $N$ 's vary slightly $1,226-1,237$ due to missing or incomplete questionnaire data

\section{Multivariate twin analyses}

Table 4 presents results of different multivariate models. In comparison with the full ACE Cholesky (Model 2), models assuming no genetic or environmental covariance across measure (Model 3), and models with no genetic influence (Model 4) fit the data poorly. In contrast, shared environmental effects were non-significant (Model 5). Results from the AE Cholesky Model (Model 5) are shown in Table 5. Heritability was highest for Stress-Reaction (0.50), depression symptoms (0.41), and Alienation (0.39). The heritability of the attachment-related anxiety dimension (0.38) was somewhat greater than the heritability of the attachment-related avoidance dimension (0.27). Depression, attachment dimensions, stress-reaction and alienation shared moderate-to-strong degrees of genetic effects $(\mathrm{Rg}=0.39-0.70)$. Attachment-related anxiety showed stronger genetic overlap with depression and measures of neuroticism than attachment-related avoidance. Nonshared environmental factors accounted for the majority of variance in each of the five characteristics
(50-73\%). While nonshared environmental correlations across variables were significant, overall they were markedly smaller than the respective genetic correlations $(\operatorname{Re}=0.14-0.46)$.

Several sub-models were then tested to develop a more parsimonious explanation of the genetic and environmental covariance structure using Model 5 as the comparison model. Dropping either the genetic (Model 6) or nonshared environmental covariance (Model 7) resulted in a significant decrease in fit, indicating that both genes and environments contribute to correlations across measures. Similarly, assuming that genetic covariance across measures comes from a single underlying factor (Model 8) also resulted in a significantly poorer fit. Because the attachment dimensions were derived from the same scale, as were Stress-Reaction and Alienation, we tested whether allowing for correlation of measure-specific genetic factors for these pairs of variables as well as a common genetic factor improved model fit. Model 10, which accounts for additional genetic commonality between the two attachment measures offered the best balance of parsimony and goodness of fit, judged by both the AIC and BIC, and the non-significant change in fit $\left(\chi_{(4)}^{2}=4.97, p=0.29\right)$. Further attempts to simplify the structure of non-shared environmental influences (E) in a similar manner led to worse fit (Models 11-13).

Figure 1 depicts the standardized genetic path coefficients linking the measures of attachment, depression, and Stress-Reaction and Alienation from Model 10. Squaring and summing the standardized path coefficients for each measure provides an estimate of the proportion of variance accounted for by genetic influences. Common genetic influences accounted for $32.5 \%$ of the variance in

Table 3 Cross-trait and cross-twin correlations for monozygotic (below the diagonal) and dizygotic (above the diagonal) twins

\begin{tabular}{|c|c|c|c|c|c|c|c|c|c|c|}
\hline & \multicolumn{2}{|l|}{ CES-D } & \multicolumn{2}{|c|}{ Avoidant attachment } & \multicolumn{2}{|c|}{ Anxious attachment } & \multicolumn{2}{|c|}{ Stress reaction } & \multicolumn{2}{|c|}{ Alienation } \\
\hline & Twin A & Twin B & Twin A & Twin B & Twin A & Twin B & Twin A & Twin B & Twin A & Twin B \\
\hline CES-D: twin A & & 0.27 & 0.31 & 0.09 & 0.40 & 0.14 & 0.54 & 0.25 & 0.55 & 0.14 \\
\hline CES-D: twin B & 0.41 & & 0.02 & 0.47 & 0.05 & 0.54 & 0.24 & 0.68 & 0.24 & 0.63 \\
\hline Avoidant attachment: twin A & 0.41 & 0.19 & & 0.11 & 0.51 & 0.04 & 0.17 & 0.05 & 0.30 & 0.03 \\
\hline Avoidant attachment: twin B & 0.14 & 0.34 & 0.27 & & 0.12 & 0.45 & 0.17 & 0.35 & 0.15 & 0.39 \\
\hline Anxious attachment: twin A & 0.45 & 0.29 & 0.34 & 0.17 & & 0.15 & 0.43 & 0.11 & 0.42 & 0.05 \\
\hline Anxious attachment: twin B & 0.21 & 0.50 & 0.16 & 0.45 & 0.36 & & 0.19 & 0.46 & 0.19 & 0.46 \\
\hline Stress reaction A & 0.56 & 0.41 & 0.31 & 0.16 & 0.46 & 0.26 & & 0.26 & 0.42 & 0.15 \\
\hline Stress reaction B & 0.32 & 0.62 & 0.15 & 0.21 & 0.33 & 0.49 & 0.54 & & 0.22 & 0.51 \\
\hline Alienation A & 0.52 & 0.32 & 0.29 & 0.11 & 0.38 & 0.20 & 0.48 & 0.30 & & 0.25 \\
\hline Alienation B & 0.16 & 0.47 & 0.16 & 0.22 & 0.21 & 0.40 & 0.31 & 0.54 & 0.34 & \\
\hline
\end{tabular}

Notes. Pearson correlations for monozygotic (MZ) twin pairs are below the diagonal; correlations for dizygotic (DZ) twins are above the diagonal. Twins in a pair were randomly designated as the "A" twin or "B" twin. Significant correlations are in bold numbers. All correlations above 0.13 are significant at $p<0.05$; correlations above 0.15 are significant at $p<0.01$ or better. $N$ 's vary slightly due to missing data for some participants. $N=334-338 \mathrm{MZ}$ pairs; 277-279 DZ pairs 
Table 4 Multivariate genetic model comparisons

\begin{tabular}{|c|c|c|c|c|c|c|c|c|c|c|c|}
\hline \multirow{3}{*}{$\begin{array}{l}\text { Model number } \\
1\end{array}$} & \multicolumn{3}{|c|}{ Model } & \multirow{3}{*}{$\begin{array}{l}-2 \mathrm{LL} \\
10149.50\end{array}$} & \multirow{3}{*}{$\begin{array}{l}\mathrm{k}^{\mathrm{a}} \\
110\end{array}$} & \multirow{3}{*}{$\begin{array}{l}\chi^{2} \\
-\end{array}$} & \multirow{3}{*}{$\begin{array}{l}\text { df } \\
-\end{array}$} & \multirow{3}{*}{$\begin{array}{l}p \\
-\end{array}$} & \multirow{3}{*}{$\begin{array}{l}\text { Model comparison } \\
-\end{array}$} & \multirow{3}{*}{$\begin{array}{l}\text { AIC } \\
-\end{array}$} & \multirow{3}{*}{$\begin{array}{l}\text { BIC } \\
-\end{array}$} \\
\hline & \multicolumn{3}{|c|}{ Saturated model } & & & & & & & & \\
\hline & A & $\mathrm{C}$ & $\mathrm{E}$ & & & & & & & & \\
\hline 2 & $\mathrm{Ch}$ & $\mathrm{Ch}$ & $\mathrm{Ch}$ & 10227.36 & 45 & 77.87 & 65 & 0.13 & 1 & -1800.64 & -14186.34 \\
\hline 3 & $\mathrm{~S}$ & $\mathrm{~S}$ & $S$ & 11757.78 & 15 & 1530.42 & 30 & 0.00 & 2 & -330.22 & -13517.41 \\
\hline 4 & 0 & $\mathrm{Ch}$ & $\mathrm{Ch}$ & 10261.62 & 30 & 34.26 & 15 & 0.003 & 2 & -1796.38 & -14217.35 \\
\hline 5 & $\mathrm{Ch}$ & 0 & $\mathrm{Ch}$ & 10235.23 & 30 & 7.87 & 15 & 0.93 & 2 & -1822.77 & -14230.54 \\
\hline 6 & $\mathrm{~S}$ & 0 & $\mathrm{Ch}$ & 10373.39 & 20 & 138.16 & 10 & 0.00 & 5 & -1704.61 & -14193.56 \\
\hline 7 & $\mathrm{Ch}$ & 0 & S & 10539.62 & 20 & 304.39 & 10 & 0.00 & 5 & -1538.38 & -14110.44 \\
\hline 8 & $\mathrm{~F}^{*}$ & 0 & $\mathrm{Ch}$ & 10247.61 & 25 & 12.38 & 5 & 0.03 & 5 & -1820.39 & -14240.40 \\
\hline 9 & $\mathrm{~F}^{* \mathrm{~b}}$ & 0 & $\mathrm{Ch}$ & 10246.74 & 26 & 11.52 & 4 & 0.02 & 5 & -1819.26 & -14237.63 \\
\hline 10 & $\mathrm{~F}^{* \mathrm{c}}$ & 0 & $\mathrm{Ch}$ & 10240.19 & 26 & 4.97 & 4 & 0.29 & 5 & -1825.81 & -14240.90 \\
\hline 11 & $\mathrm{~F}^{* \mathrm{c}}$ & 0 & $\mathrm{~F}^{*}$ & 10282.95 & 21 & 42.76 & 5 & 0.00 & 10 & -1793.05 & -14235.57 \\
\hline 12 & $\mathrm{~F}^{* \mathrm{c}}$ & 0 & $\mathrm{~F}^{* \mathrm{c}}$ & 10258.29 & 22 & 18.13 & 4 & 0.00 & 10 & -1815.71 & -14244.69 \\
\hline 13 & $\mathrm{~F}^{* \mathrm{c}}$ & 0 & $\mathrm{~F}^{* \mathrm{~b}}$ & 10278.19 & 22 & 38.00 & 4 & 0.00 & 10 & -1795.81 & -14234.74 \\
\hline
\end{tabular}

$A$ Genetic influences; $C$ shared environment; $E$ unique environment; $C h$ Cholesky decomposition; $S$ specific factors only; $F$ common factor only; $F^{*}$ common factor plus specific factors; $O$ variance structure omitted from model; AIC Akaike's Information Criterion; BIC Bayesian Information Criterion

${ }^{\mathrm{a}}$ Model parameter $(\mathrm{k})$ excludes parameters estimated for means (20 means)

${ }^{\mathrm{b}}$ Extra parameter to account for genetic (or unique environmental) commonality between neuroticism measures

${ }^{c}$ Extra parameter to account for genetic (or unique environmental) commonality between attachment measures

Table 5 Heritability estimates, genetic correlations and environmental correlations from the AE Cholesky model (Model 5)

\begin{tabular}{|c|c|c|c|c|c|}
\hline & 1 & 2 & 3 & 4 & 5 \\
\hline \multicolumn{6}{|l|}{ Genetic variance: $\mathrm{Rg}$} \\
\hline 1. Depression symptoms & $0.41(0.32,0.48)$ & & & & \\
\hline 2. Avoidant attachment & $0.48(0.30,0.64)$ & $0.27(0.18,0.36)$ & & & \\
\hline 3. Anxious attachment & $0.58(0.43,0.70)$ & $0.58(0.41,0.72)$ & $0.38(0.30,0.46)$ & & \\
\hline 4. Stress-reaction & $0.83(0.73,0.92)$ & $0.39(0.21,0.56)$ & $0.65(0.52,0.77)$ & $0.50(0.43,0.57)$ & \\
\hline 5. Alienation & $0.70(0.58,0.82)$ & $0.47(0.27,0.65)$ & $0.53(0.37,0.67)$ & $0.67(0.55,0.78)$ & $0.39(0.30,0.47)$ \\
\hline \multicolumn{6}{|c|}{ Unique environmental variance: $\mathrm{Re}$} \\
\hline 1. Depression symptoms & $0.59(0.52,0.67)$ & & & & \\
\hline 2. Avoidant attachment & $0.33(0.24,0.43)$ & $0.73(0.64,0.82)$ & & & \\
\hline 3. Anxious attachment & $0.35(0.26,0.43)$ & $0.46(0.39,0.54)$ & $0.62(0.54,0.70)$ & & \\
\hline 4. Stress-reaction & $0.31(0.22,0.39)$ & $0.14(0.04,0.23)$ & $0.25(0.16,0.34)$ & $0.50(0.43,0.57)$ & \\
\hline 5. Alienation & $0.34(0.25,0.42)$ & $0.22(0.12,0.31)$ & $0.27(0.17,0.35)$ & $0.30(0.21,0.39)$ & $0.61(0.53,0.70)$ \\
\hline
\end{tabular}

Note. Heritability estimates presented in bold text on diagonals of the top half of the table. Proportion of variance due to unique environmental factors presented in bold text on diagonals of the bottom half of the table. Genetic correlations ( $\mathrm{Rg}$ ) and unique environmental correlations (Re) across variables presented in off-diagonals of the top and bottom half of the table (respectively). 95\% confidence intervals in parenthesis

depressive symptoms, $6.3 \%$ of the variance in attachmentrelated avoidance, $17.6 \%$ of the variance in attachmentrelated anxiety, $43.6 \%$ of the variance in Stress-Reaction, and $21.1 \%$ of the variance in Alienation. We found significant measure-specific genetic factors for all measures except Stress-Reaction. Measure-specific genetic factors accounted for only 7.2 and $6.8 \%$ of the variance in depressive symptoms and Stress-Reaction, respectively. In contrast, measure-specific genetic factors accounted for modest proportions of variance in Alienation (16.0\%), attachment-related avoidance (19.4\%) and attachmentrelated anxiety $(21.1 \%)$. Measure-specific genetic factors influencing the attachment dimensions were also moderately correlated $(\mathrm{Rg}=0.41)$. Nearly all $(81.7 \%)$ of the total genetic variance in depressive symptoms and StressReaction (86.6\%) was accounted for by the common 
genetic factor. In contrast, the majority $(75.6 \%)$ of genetic variance in attachment-related avoidance was due to the measure-specific genetic factor that was partially shared with attachment-related anxiety. Genetic variance in attachment-related anxiety, in contrast, was more evenly divided among common (45.5\%) and measure-specific genetic factors $(64.5 \%)$, as was the genetic variance in Alienation (56.9\% common, $43.1 \%$ measure-specific).

Figure 2 presents the nonshared environmental covariance structure from the Cholesky decomposition in Model 10 ; only one parameter estimate was not statistically significant. Although the significant parameters indicate that there is some degree of overlap of nonshared environmental factors, overall-unlike the genetic effects-most of the effects of nonshared environment were measurespecific. For instance, squaring the path coefficients from E1 to the CES-D shows that nonshared environmental influences accounted for $59 \%$ of the variance in depressive symptoms. The E1 factor, however, account for only $9 \%$ of the variance in attachment-related avoidance, $6.8 \%$ in attachment-related anxiety, $4.8 \%$ in Stress-Reaction, and $7.8 \%$ in Alienation. Similarly, nonshared environmental influences on (path E2) account for $66 \%$ of the variance in attachment-related avoidance but only $8 \%$ of the variance in the anxious attachment dimension. Thus, there are measure-specific nonshared environmental factors that influence each characteristic with minimal influence on other characteristics.

\section{Discussion}

Estimates of genetic contributions to the attachment-related anxiety dimension (38\%) were comparable to those in previous studies (Brussoni et al. 2000; Crawford et al. 2007a, b; Donnellan et al. 2008; Torgersen et al. 2007). This suggests that genetic and environmental contributions to anxious attachment may be robust across different populations and measures. Notably, consistent with Donnellan et al. (2008), we found modest but significant genetic contributions to the attachment-related avoidance dimension (27\%). Unlike Crawford et al. (2007a, b) and Brussoni et al. (2000), we saw no evidence supporting the role of common environmental influences (e.g., possible influences from childhood exposure to parents) on dimensions of adult romantic attachment. Attachment theory tends to focus on the role of family or social environment in shaping attachment style. However, by midlife, unique experiences in different romantic relationships may be more consequential for the twins' attachment. Estimates of heritability for depression symptoms and indices of negative emotionality were also largely comparable to those in previous research (range 0.39-0.50).
Virtually all of the genetic covariance between the attachment dimensions, depressive symptoms, and negative emotionality is accounted for by a common genetic factor, with highest loadings for depressive symptoms and StressReaction. This common genetic factor is consistent with previous work that found a non-specific "genetic distress" factor linking anxiety and depression (Kendler et al. 1987a, b). Our results also support prior research showing genetic overlap between continuous measures of anxious attachment and measures of neuroticism (Crawford et al. 2007a, b; Donnellan et al. 2008). This is consistent with findings that depression, neuroticism, and relationship difficulties have shared risk factors in men (Kendler et al. 2006a, b).

Importantly, the present study supports the view that dimensions of attachment-related anxiety and avoidance are only partly overlapping constructs and that they are also distinguishable from depressive symptoms and personality traits such as negative emotionality. First, the heritability of attachment-related anxiety was somewhat higher than the heritability of the attachment-related avoidance dimension. Second, both attachment-related anxiety and avoidance showed measure-specific genetic influences which were only partially overlapping $(\mathrm{Rg}=0.41)$. Third, patterns of correlations with depressive symptoms and indices of neuroticism varied across attachment dimension. Specifically, the Cholesky results showed a greater overlap of genetic factors $(\mathrm{Rg})$ with attachment-related anxiety compared to attachment-related avoidance $(\operatorname{Rg}=0.53-0.65$ vs. $\mathrm{Rg}=0.39-0.48)$. Similarly, from our best-fitting model, only a minority of the genetic variance in attachmentrelated avoidance $(24.4 \%)$ was due to common genetic factors which also influenced the other measures; in contrast, these common genetic factors accounted for nearly half $(45.5 \%)$ of the total genetic variance in the attachmentrelated anxiety measure. Finally, the complex pattern of unique environmental correlations suggests little overlap in the types of experiences that contribute to the development of relational difficulties or psychological distress.

Previous twin studies on adult romantic attachment vary widely in measures used to assess attachment, sample sizes, and composition of the samples (e.g., age, gender). Despite this variability, results for measures assessing anxious romantic attachment appear to be fairly consistent across adult twin studies. Although evidence for the role of genetic and environmental influences on attachment-related avoidance in romantic relationships is mixed, one consistent finding is the heritability of avoidance is lower than the heritability of attachment-related anxiety. One explanation may be that attachment-related avoidance is less strongly rooted in temperament than attachment-related anxiety. This is supported by the fact that correlations between measures of neuroticism and attachment-related anxiety tend to range from 0.4 to 0.5 while associations 
between attachment-related avoidance and personality measures tend to be much lower ( $\sim 0.2$ to 0.3 ) (Noftle and Shaver 2006). The lower heritability does not seem to be due to measurement error; since the internal consistency estimates, means, and standard deviations for both measures are roughly equivalent. The dismissiveness and detachment of attachment-related avoidance may reflect a learned coping mechanism for dealing with exposure to particularly untrustworthy relationships. By being dismissive and emotionally distant in relationships, avoidantly attached adults may be less likely to have opportunities for positive relational experiences that might moderate or mediate their avoidance.

\section{Limitations}

This study uses a large sample of predominantly white nonHispanic men; we do not know whether our results generalize to women or other ethnicities. However previous twin studies included very few men. Another limitation of this study was the use of a self-report measure of adult romantic attachment. Child and clinical studies of attachment generally use intensive lengthy interview or observational methods. Although the Experiences in Close Relationships Inventory is one of the most commonly used self-report measures of adult romantic attachment and has been validated in many studies, it may be that using a selfreport measure rather than an interview to assess attachment increases the likelihood of finding genetic covariance with self-report measures of anxiety or depression. Other researchers have found associations between attachment dimensions and "big five" personality traits such as extraversion. Because our specific focus was on differentiating attachment dimensions from depression symptoms and measures reflecting "neuroticism," we did not examine the role of other personality traits such as extraversion, openness-to-experience or conscientiousness (Noftle and Shaver 2006). Finally, our results are uninformative about the nature of environmental and genetic influences on earlier (i.e., infant or childhood) attachments or on attachment relationships with other significant adults. We do, however, focus on an understudied developmental transition period-middle age.

The unique contribution of this study is the finding that dimensions of attachment are not interchangeable with each other or with other measures. Other, related, research shows that knowledge of an individual's problems with attachment contributes valuable additional information over and above depression symptoms or negative traits. Conradi and de Jonge (2008) for instance, found worse outcomes across 3 years for anxiously attached depressed patients compared with depressed patients with other attachment styles. Behavioral patterns involving emotional disengagement from and wariness about intimate others (i.e., attachmentrelated avoidance) may become more consequential with aging when more assistance is needed from others or when loved ones become unavailable (Franz and White 1985). Further, depressive symptoms increase between the ages of 60 and 80 in men, and are associated with greater risk for suicide especially when accompanied by social isolation or anxiety (Gonda et al. 2007; Wiktorsson et al. 2010). We predict greater morbidity and mortality among older men with tendencies to be avoidantly attached, especially if accompanied by depressive symptoms.

This research also shows that environments strongly influence whether we feel connected to (or disconnected from) intimate others. Future research needs to identify what environmental influences across the life course are most consequential for relational well-being. Genetically informative longitudinal studies on dimensions of relational attachment can help to illuminate the role of relationshipbased risk and resilience factors in healthy aging (Bifulco et al. 2002a, b; O'Connor et al. 2000; Shaver and Mikulincer 2004) and contribute to the development of effective interventions for older adults. With the longitudinal data being collected in the VETSA study, we will be able to examine questions such as whether genetic and environmental influences vary as a function of age, how attachment mediates the impact of particular life experiences in later life (e.g., bereavement, changes in marital status, caregiving, health problems, retirement), and what types of experiences are most likely to influence attachment.

Acknowledgments Research was supported by NIH grants R01 AG018386, R01 AG022982, and R01 AG018384 and Training Grant MH-20030. The U.S. Department of Veterans Affairs provides financial support for the development and maintenance of the Vietnam Era Twin (VET) Registry. Numerous organizations provided invaluable assistance in the conduct of this study, including: Department of Defense; National Personnel Records Center, National Archives and Records Administration; Internal Revenue Service; National Opinion Research Center; National Research Council, National Academy of Sciences; the Institute for Survey Research, Temple University. Most importantly, the authors gratefully acknowledge the continued cooperation and participation of the members of the VET Registry and their families. We also appreciate the time and energy of many staff and students who assisted with the VETSA study.

Open Access This article is distributed under the terms of the Creative Commons Attribution Noncommercial License which permits any noncommercial use, distribution, and reproduction in any medium, provided the original author(s) and source are credited.

\section{References}

Akaike H (1987) Factor analysis and AIC. Psychometrika 52:317-332 Bifulco A, Moran P, Ball C, Bernazzani O (2002a) Adult attachment style. I: its relationship to clinical depression. Soc Psychiatry Psychiatr Epidemiol 37:50-59 
Bifulco A, Moran P, Ball C, Lillie A (2002b) Adult attachment style. II: its relationship to psychosocial depressive-vulnerability. Soc Psychiatry Psychiatr Epidemiol 37:60-67

Bowlby J (1982) Attachment and loss: retrospect and prospect. Am J Orthopsychiatr 52:664-678

Bowlby J (1988) A secure base: clinical applications of attachment theory. Brunner-Routledge, East Sussex

Brennan KA, Clark CL, Shaver PR (1998) Self-report measurement of adult romantic attachment: an integrative overview. In: Simpson JA, Rholes WS (eds) Attachment theory and close relationships. Guilford, New York, pp 46-76

Brussoni M, Jang K, Livesley W, MacBeth T (2000) Genetic and environmental influences on adult attachment styles. Pers Relationsh 7:283-289

Caspi A (2000) The child is father of the man: personality continuities from childhood to adulthood. J Pers Soc Psychol 78:158-172

Caspi A, Begg D, Dickson N, Harrington H, Langley J, Moffitt TE, Silva PA (1997) Personality differences predict health-risk behaviors in young adulthood: evidence from a longitudinal study. J Pers Soc Psychol 73:1052-1063

Conradi HJ, de Jonge P (2008) Recurrent depression and the role of adult attachment: a prospective and a retrospective study. J Affect Disord 116:93-99

Crawford TN, Livesley WJ, Jang KL, Shaver PR, Cohen P, Ganiban J (2007a) Insecure attachment and personality disorder: a twin study of adults. Eur J Pers 21:191-208

Crawford TN, Shaver PR, Goldsmith HH (2007b) How affect regulation moderates the association between anxious attachment and neuroticism. Attach Hum Dev 9:95-109

Donnellan MB, Burt SA, Levendosky AA, Klump KL (2008) Genes, personality, and attachment in adults: a multivariate behavioral genetic analysis. Pers Soc Psychol Bull 34:3-16

Eaves LJ, Heath AC, Neale MC, Hewitt JK, Martin NG (1998) Sex differences and non-additivity in the effects of genes on personality. Twin Res Hum Genet 1:131-137

Eisen SA, True WR, Goldberg J, Henderson W, Robinette CD (1987) The Vietnam Era Twin (VET) Registry: method of construction. Acta Genet Med Gemellol (Roma) 36:61-66

Eisen SA, Neuman R, Goldberg J, Rice J, True W (1989) Determining zygosity in the Vietnam Era Twin Registry: an approach using questionnaires. Clin Genet 35:423-432

Fanous AH, Neale MC, Aggen SH, Kendler KS (2007) A longitudinal study of personality and major depression in a population-based sample of male twins. Psychol Med 37:1163-1172

Fraley RC, Waller NG (1998) Adult attachment partners: a test of the typological model. In: Simpson JA, Rholes WS (eds) Attachment theory and close relationships. Guilford, New York, pp 77-114

Franz CE, White KW (1985) Individuation and attachment in personality development: extending Erikson's theory. J Pers 53:224-256

Franz CE, Lyons MJ, O'Brien RC, Panizzon M, Kim K, Bhat R, Grant MD, Toomey R, Eisen S, Xian H, Kremen WS (in press) A 35-year longitudinal assessment of cognition and midlife depression symptoms: the Vietnam Era Twin Study of Aging. Am J Geriatr Psychiatry [Epub ahead of print]

Gonda X, Fountoulakis KN, Kaprinis G, Rihmer Z (2007) Prediction and prevention of suicide in patients with unipolar depression and anxiety. Ann Gen Psychiatry 6:23

Griffin D, Bartholomew K (1994) The metaphysics of measurement: the case of adult attachment. In: Bartholomew K, Perlman D (eds) Advances in personal relationships. Jessica Kingsley, London, pp 17-52

Hazan C, Shaver PR (1987) Romantic love conceptualized as an attachment process. J Pers Soc Psychol 52:511-524

Hettema JM, Prescott CA, Kendler KS (2004) Genetic and environmental sources of covariation between generalized anxiety disorder and neuroticism. Am J Psychiatry 161:1581-1587
Hettema JM, Kuhn JW, Prescott CA, Kendler KS (2006) The impact of generalized anxiety disorder and stressful life events on risk for major depressive episodes. Psychol Med 36:789-795

Jang KL, Livesly WJ, Vernon PA (1996) Heritability of the big five personality dimensions and their facets: a twin study. J Pers 64:577-591

Kendler KS, Heath AC, Martin NG, Eaves LJ (1987a) Symptoms of anxiety and depression in a volunteer twin population: the etiologic role of genetic and environmental factors. Arch Gen Psychiatry 43:213-221

Kendler KS, Heath AC, Martin NG, Eaves LJ (1987b) Symptoms of anxiety and symptoms of depression. Same genes, different environments? Arch Gen Psychiatry 44:451-457

Kendler KS, Gardner CO, Prescott CA (2006a) Toward a comprehensive developmental model for major depression in men. Am J Psychiatry 163:115-124

Kendler KS, Gatz M, Gardner CO, Pedersen NL (2006b) Personality and major depression: a Swedish longitudinal, population-based twin study. Arch Gen Psychiatry 63:1113-1120

Kremen WS, Thompson-Brenner H, Leung YM, Grant MD, Franz CE, Eisen SA, Jacobson KC, Boake C, Lyons MJ (2006) Genes, environment, and time: the Vietnam Era Twin Study of Aging (VETSA). Twin Res Hum Genet 9:1009-1022

Krueger RF, Caspi A, Moffitt TE (2000) Epidemiological personology: the unifying role of personality in population-based research on problem behaviors. J Pers 68:967-998

Lyons MJ, Eisen SA, Goldberg J, True W, Lin N, Meyer JM, Toomey R, Faraone SV, Merla-Ramos M, Tsuang MT (1998) A registry based twin study of depression in men. Arch Gen Psychiatry $55: 468-472$

Middeldorp CM, Cath DC, Van Dyck R, Boomsma DI (2005) The comorbidity of anxiety and depression in the perspective of genetic epidemiology. A review of twin and family studies. Psychol Med 35:611-624

Middeldorp CM, Cath DC, Beem AL, Willemsen G, Boomsma DI (2008) Life events, anxious depression and personality: a prospective and genetic study. Psychol Med 38:1557-1565

Mikulincer M, Shaver PR (2007) Attachment in adulthood: structure dynamics and change. Guilford Press, New York

Neale MC, Boker SM, Maes HH (2002) Mx: structural modeling. Virginia Commonwealth University, Department of Psychiatry, Richmond

Nichols RC, Bilbro WCJ (1966) The diagnosis of twin zygosity. Acta Genet Stat Med 16:265-275

Noftle EE, Shaver PR (2006) Attachment dimensions and the big five personality traits: associations and comparative ability to predict relationship quality. J Res Pers 40:179-208

O'Connor T, Croft C, Steele H (2000) The contributions of behavioral genetic studies to attachment theory. Attach Hum Dev 2: $107-122$

Patrick CJ, Curtin JJ, Tellegen A (2002) Development and validation of a brief form of the Multidimensional Personality Questionnaire. Psychol Assess 14:150-163

Radloff LS (1977) The CES-D scale: a self-report depression scale for research in the general population. Appl Psychol Meas 1: 385-401

Rush A, Pincus H, First M, Blacker D, Endicott J, Keith S, Phillips K, Ryan N, Smith G, Tsuang M, Widiger T, Zarin D (2000) Handbook of psychiatric measures. American Psychiatric Association, Washington, DC

Schaie KW, Zuo YL (2000) Family environments and adult cognitive functioning. In: Sternberg RL, Grigorenko E (eds) Context of intellectual development. Erlbaum, Hillsdale

Schwarz G (1978) Estimating the dimension of a model. Ann Stat 6:461-464

Seeman T, Lusignolo TM, Albert M, Berkman L (2001) Social relationships, social support, and patterns of cognitive aging in 
healthy, high-functioning older adults: MacArthur studies of successful aging. Health Psychol 20:243-255

Shaver PR, Mikulincer M (2004) Attachment in the later years: a commentary. Attach Hum Dev 6:451-464

Shaver PR, Hazan C, Bradshaw D (1988) Love as attachment: the integration of three behavioral systems. In: Sternberg RJ, Barnes ML (eds) The psychology of love. Yale University Press, New Haven, pp 68-99

Tellegen A (1985) Structure of mood and personality and their relevance to assessing anxiety, with an emphasis on self-report. In: Tuma AH, Maser JD (eds) Anxiety and the anxiety disorders. Erlbaum, Hillsdale, pp 681-706
Torgersen A, Grova B, Sommerstad R (2007) A pilot study of attachment patterns in adult twins. Attach Hum Dev 9:127-138

Tsuang MT, Bar JL, Harley RM, Lyons MJ (2001) The Harvard Twin Study of Substance Abuse: what we have learned. Harv Rev Psychiatry 9:267-279

Wiktorsson S, Runeson B, Skoog I, Ostling S, Waern M (2010) Attempted suicide in the elderly: characteristics of suicide attempters 70 years and older and a general population comparison group. Am J Geriatr Psychiatry 18:57-67 